\title{
FREIGHT TRANSPORT LOGISTICS IN THE BALTIC SEA REGION. REGIONAL ASPECTS
}

\author{
Igor Kabashkin \\ Transport and Telecommunication Institute \\ Lomonosova str. 1, Riga, LV-1019, Latvia \\ Phone:+371-67100594. Fax:+371-67100535 \\ E-mail:kiv@tsi.lv
}

\begin{abstract}
In the situation where a large increase in trade and freight transport volumes in the Baltic Sea Region (BSR) is expected and in which the BSR is facing a major economic restructuring, efforts to achieve more integrated and sustainable transport and communication links within the BSR are needed. One of these efforts is the development of logistics centres (LCs) and their networking, which will continue to have an impact on improving communication links, spatial planning practices and approaches, logistics chain development and the promotion of sustainable transport modes. These factors will reflect on logistics processes both in major gateway cities and in remote BSR areas.

The importance of logistics systems as a whole is not seen clearly enough. Logistics actors see that logistics operations are not appreciated as much as other fields of activity. In addition, logistics centres and the importance of logistics activities to the business life of areas and the employment rate should be brought up better.

In the paper main goal and tasks of national approach for LCs development are discussed. Strategic focus of new activities in this area is on the integration of various networks within and between logistics centres in order to improve and develop the quality of logistics networks as well as to spatially widen the networking activities.
\end{abstract}

Keywords: transport logistics, logistics centre, Baltic Sea region

\section{Introduction}

International business has been undergoing a period of rapid transformation. Trends towards globalisation, integrated logistics and the development of Information and Communication Technology (ICT) are all reshaping the world's trading patterns and consequently physical trade flows.

Such restructuring is contributing to economic growth, better allocation of resources and more freedom of choice for consumers, as well as increased competition. In order to be internationally competitive, businesses are organising strategic worldwide networks that can deliver an efficient and high-quality response to demand from any segment of the world market. The efficient and integrated organisation of such activities is often referred to as global logistics and it has become the core of global competitive power.

Global logistics networks serve as a circulatory system for the corresponding global value-adding chain where various components in the logistics network serve different functions in an organisationally unified manner. Therefore, in order to establish a region as a key component in global logistics networks, it is necessary to create a vision of how to position the region strategically within the context of the overall global logistics networks. To achieve this objective, governments both individually and collectively will need to develop and implement systematic policies for realising the vision (Figure 1). The essence of this global logistics competence also applies to the private sector.

Aim of the study is to analyse of the main factors of influence for regional development of global transport logistics in the transit countries as the case study for Baltic Sea Region (BSR).

In the paper main goal and tasks of national approach for network of logistics centres (LC) development are discussed. Strategic focus of new activities in this area is on the integration of various networks within and between logistics centres in order to improve and develop the quality of logistics networks as well as to spatially widen the networking activities. 


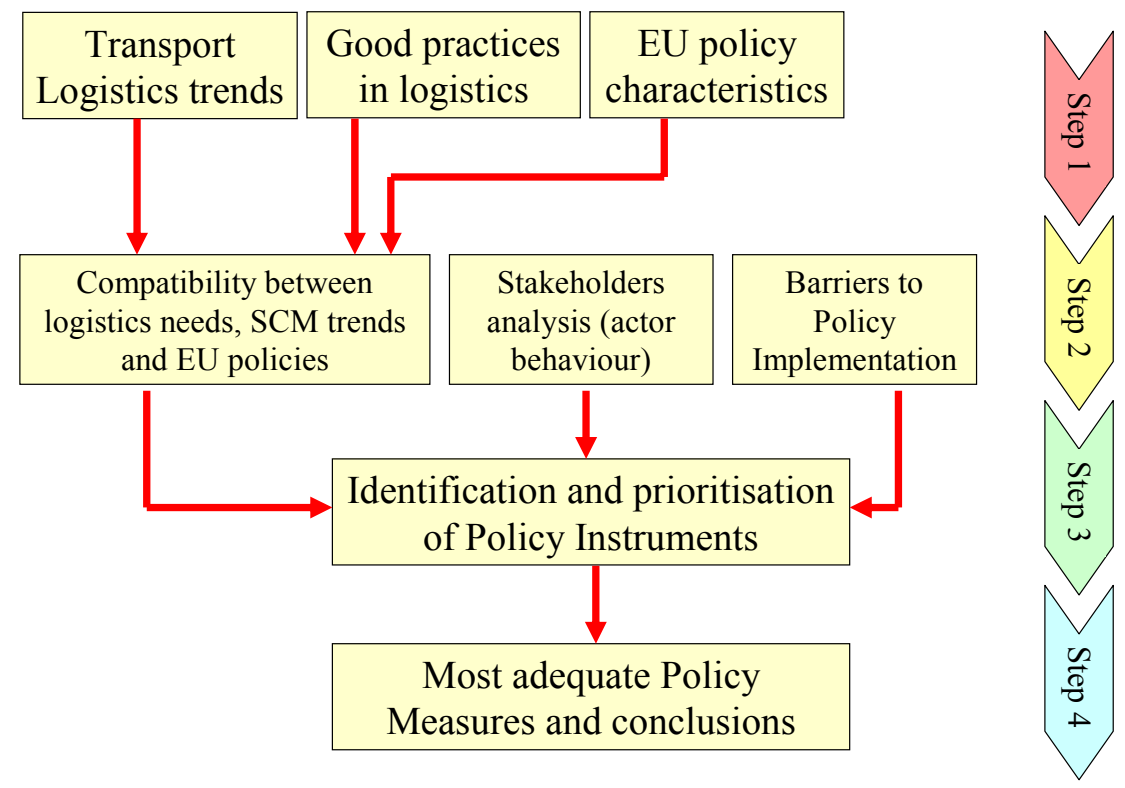

Figure 1. General structure of regional transport logistics development

\section{Global Logistics Trends and Freight Transport Development in the Baltic Sea Region}

Development pattern of the particular sectors within the EU transport system is quite unbalanced which is preconditioned by the following factors: first of all, the extent of the particular countries involvement into the work of the transport industry varies from country to country; secondly, it is influenced substantially by the pattern of the EU financial packages allocation. Nowadays one of the top priorities of the EU transport policy is the expansion of the Trans-European networks (the possibility is envisaged even to stretch them outside the EU borders), as well as building up the global transport corridors in cooperation with other countries.

Any strategy adopted for the purposes of the transport system development is worth of mark since it contains two split-level components. One of these components is of a global character: today the appropriate infrastructure including transport must be ensured to guarantee a successful development of a given region. This assumption quite logically leads us to the next level - the EU specifically formulated practical proposals and problem-solving strategies. The same two-level approach can be used to describe the EU transport policy. However, when stipulating the EU transport policy, one has to take into account a major impact it confronts due to the influence of political and economic factors.

The Baltic region is remarkable for its economically advantageous geographical position within the Eurasian transport system, connecting Russia with the biggest world markets of the Central and Eastern Europe as well as with the Baltic States and the CIS States. In this context the relationship between the European Union and Russia in the specified region is being determined by two major trends.

The first trend can be characterized by a significant enhancement of the St.Petersbourg port's throughput in combination with maintaining an appropriate capacity level of the railway trunks ensuring cargo transportation to the required destinations. The other trend is related to limitations adopted in order to curb a constant increase of the modern container carrier's dimensions. It has been stated in the document issued by the Transport Regulatory Council of the European Transport Ministers' Organization CEMT [1] that Malaccamax class vessels with 18000 TEU, $200000 \mathrm{t}$ draught, 740m long and $60 \mathrm{~m}$ wide will be the ultimate limit reached in the process of such container carriers' enlargement. The reason is simple: any vessel being a bigger one will not be physically able to cross the Malaccan Strait neither the Suez Channel.

The above-mentioned factor gives an account of the fact that Goethebourg is currently viewed as the largest (to follow St.Petersbourg though) container handling port at the Baltic Sea, since Goethebourg is the last but not least Baltic port which has retained its capacity to handle the container carriers of the above-specified class. 


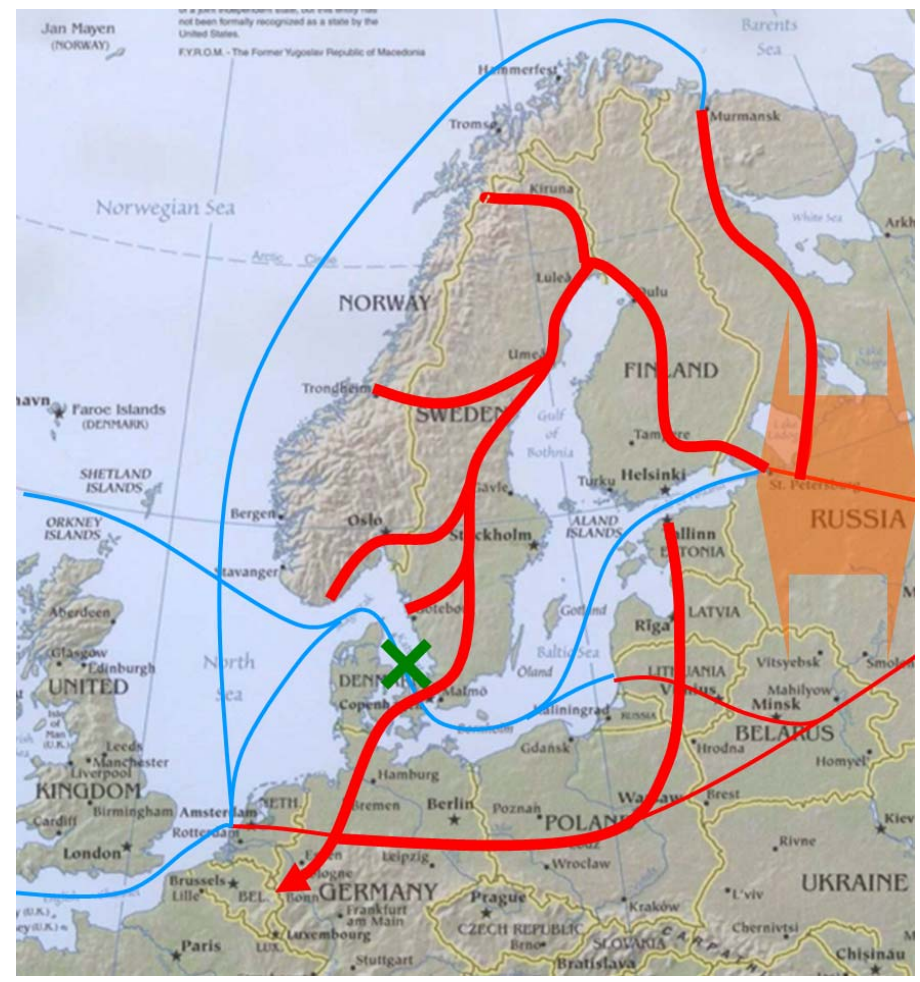

Figure 2. The Transport System of the Baltic Sea Region

The presence of two major Ports performing cargo flows integration and uniting the opposite ends of the Baltic Sea requires to ensure an appropriate development of the inland maritime feeder connections and/or local railroad trunks capable of shipping cargos to the customers located in the inner region of the Baltic Sea (Figure 2). This actually explains why TEN-T Development Programme adopted by the EU has pointed out, among the others, only two Projects related to the above-specified region, namely:

- $\quad$ sea ways development (the project Motorway of the Baltic Sea) and

- development of the railway connection uniting the Baltic States of Estonia, Latvia and Lithuania with the Central Europe (the project Rail Baltica).

The last project also serves as an important link ensuring the completion of the circular railroad building around the Baltic Sea (Figure 3) as defined in the document [1].

Notwithstanding the fact that Rail Baltica Project does not manifest connection set up with St.Petersbourg, such connection availability is actually implied by nearly all researches conducted in relation with the named project. It can be easily explained from the practical point of view: the international logistics sees the Baltic ports quite fit into the united railroad network of Russia due to the historical compliance of their rail gages, whereas the St.Petersbourg`s ports throughput is currently inadequate and not able to handle all cargos heading to/from Russia (it can be also reminded that ice formation at the ports of the specified region reduces significantly their scope of operation in winter).

Another factor to determine the close cooperation between Russia and the Baltic countries is the level of the provided logistic services. In 2010 the World Bank published its periodic research on the quality of logistic handling (services) provided in 155 countries [2]. The relevant analysed data demonstrates that currently the logistic handling index in the EU States bordering with Russia is at least twice higher versus the level of logistic handling provided domestically (Figure 4).

This certainly is a powerful incentive encouraging both Russian and international commercial structures to use more efficient logistic tools available in the neighbouring states in course of their transportation activity.

When addressing the tendencies of cooperation development between Russia and the EU, we have to take into account the dynamics of the practical steps taken to promote further development of the cargo logistic activities within Europe. Leaving Russia behind in terms of provided logistic services, the countries of Europe make significant efforts to promote development of their logistic capabilities, which results in, for example, establishing and subsequent realization of the Freight Transport Logistics Action Plan [3]. 


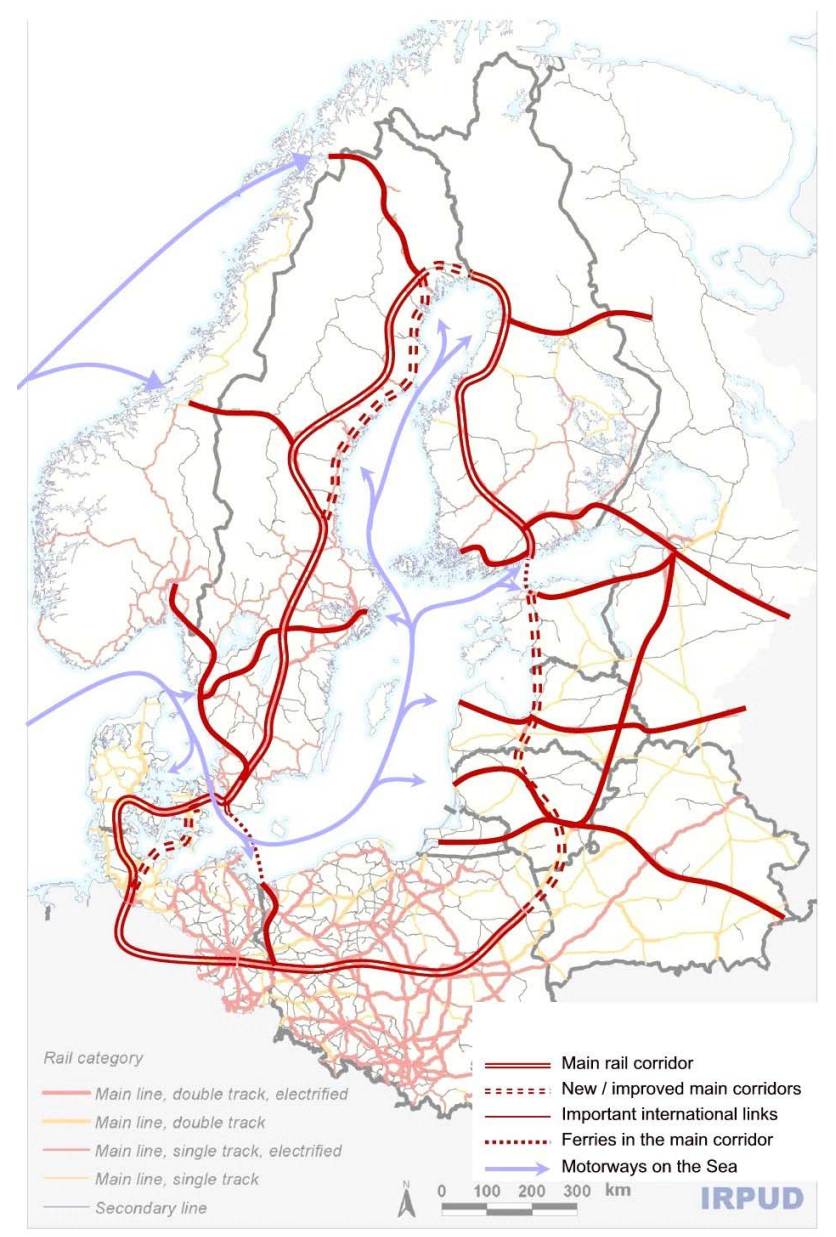

Figure 3. The Baltic Circular Railroad

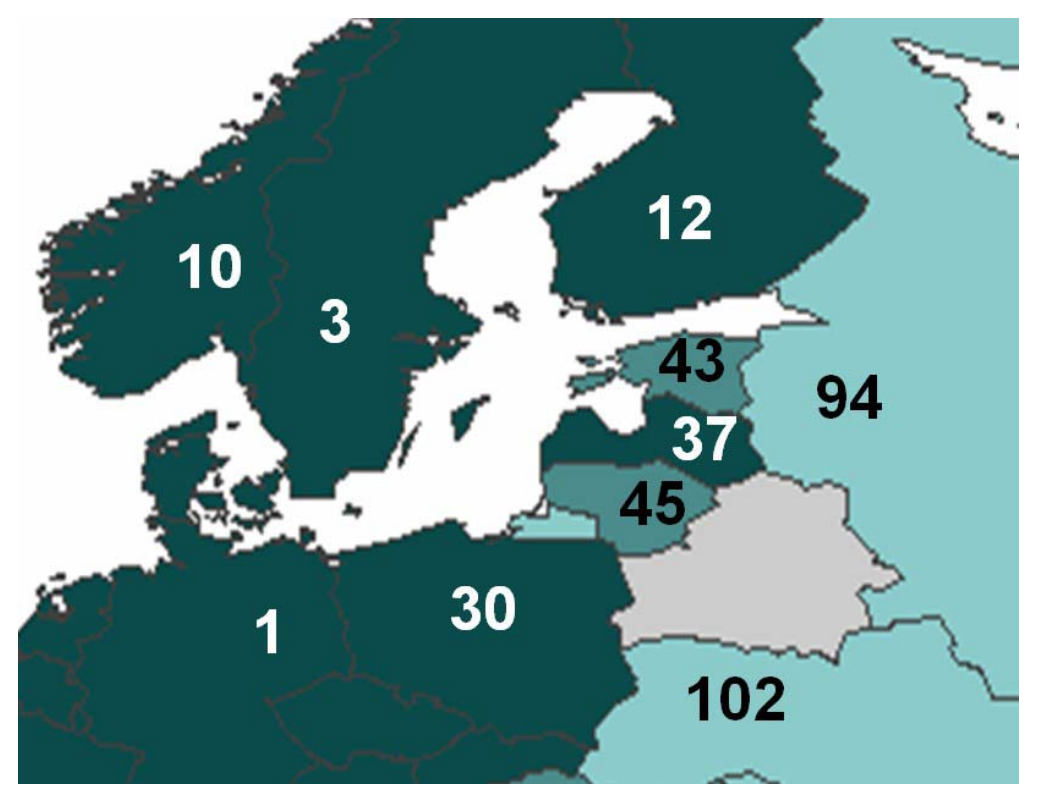

Figure 4. BSR countries rating in according of Logistic Performance Index

The process of the united customs alliance establishment as well as the measures undertaken to build a common economic area for Russia, Belarus and Kazakhstan require adopting similar unanimous 
and simultaneous actions in order to set up the identical programmes designed to boost the efficiency of the cargo logistic transportation within the frameworks of the prospective alliance as well as in interface with the EU. The Baltic countries play an important role in this process since their borders is the main meeting point of the two above-mentioned global economic unions.

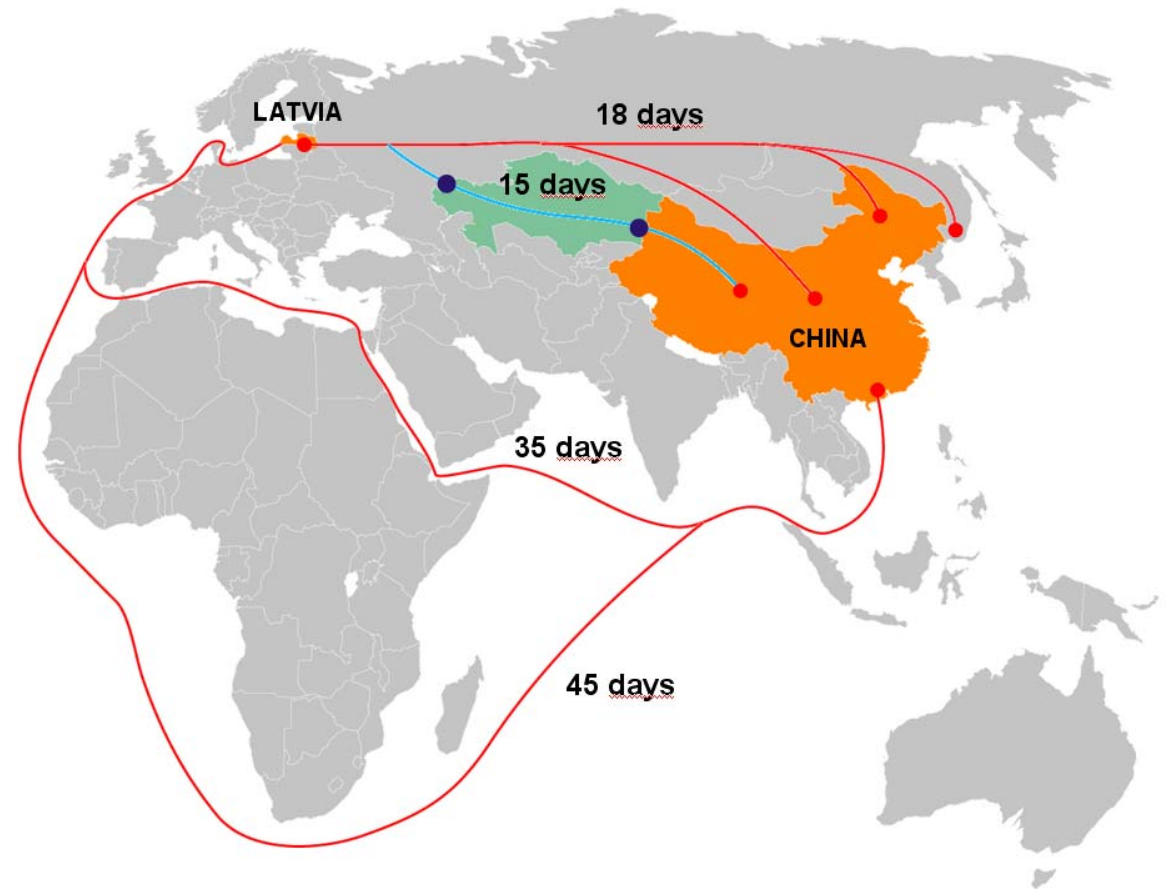

Figure 5. The Global Transit Directions within the Eurasian continent

One can not but considers another important factor of globalisation. The rapidly progressing development of labour force in the continental Western part of China can be treated as an urgent appeal to set up some new transportation patterns instead of the traditional sea transportation used habitually during the recent years (Figure 5). Under these circumstances the common custom area of Russia, Belarus and Kazakhstan serves as a vast transit area where operational efficiency is determined not only through transport system coordinated development in the EU states, but also due to the high efficiency of all procedures covering cooperation with the EU that acts both as the end user and supplier in the specified global logistic chain.

It can be noted that the Baltic countries due to the external circumstances have a unique opportunity to complete their mission of being an important linking element between two major economical unions in the frameworks of the Trans-continental international logistic chain.

Globalisation and intensive need to integrate the Eurasian continental transport systems, including Chinese transport and logistics systems, generate the new challenges to be met and require the novel problem-solving strategies to be implemented in the framework of the interdependent international logistic chain of the continent. To ensure such strategies are successful, it would be necessary to work out a coordinated activity plan adopted by all the participants to the described process. Building an efficient logistic chain is impossible without a mutual cooperation between its entire links - participants from various countries. Once we realize the utmost importance of this idea, we are ready to provide a steady successful development of the national transport and logistic systems.

\section{Logistics Centres in the Baltic Sea Region}

In the situation where a large increase in trade and freight transport volumes in the Baltic Sea Region (BSR) is expected and in which the BSR is facing a major economic restructuring, efforts to achieve more integrated and sustainable transport and communication links within the BSR are needed. One of these efforts is the development of logistics centres (LCs) and their networking, which will continue to have an impact on improving communication links, spatial planning practices and approaches, logistics chain development and the promotion of sustainable transport modes. New concepts, such as dry ports, are additional extensions of traditional LC networks [5]. 
Firstly, as it is illustrated on Figure 1, the barrier analysis seems to indicate that obstacles to implementation of logistics measures at the strategic level stem mainly from resistance on the part of certain stakeholders to implementation of some measures based on an assessment of costs and benefits and secondly, because of possible inconsistencies in the division of responsibilities (competencies) in the implementation of particular measures, calling for a cautious 4 step approach to policy implementation where opposition effects should be mitigated in order to achieve smooth implementation of policy measures.

In this case it is very important to know the point view of different stakeholders on local logistics development. This paper includes summary of interviews of transport policy makers, logistics operators, spatial planners in Latvia about the spatial planning need of logistics centres and about the state of co-operation between logistics operators and spatial planners in this question [4]. The main purpose of interview is collecting opinion on the logistics centres and concerning problems from the point of view of different actors (Figure 6).

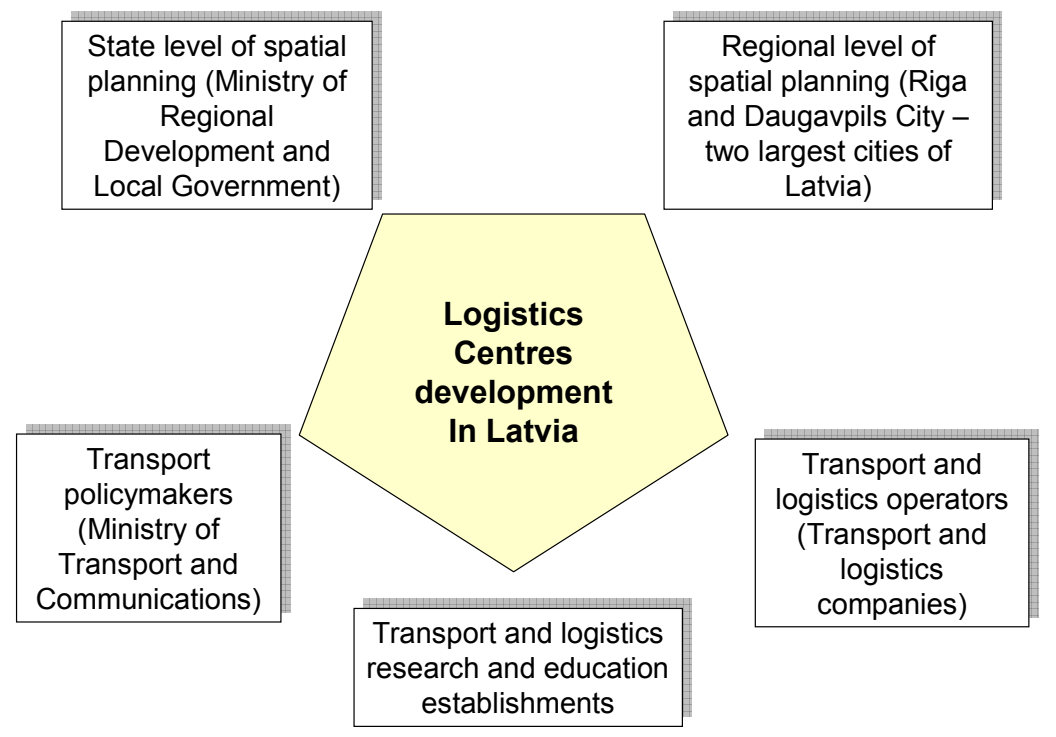

Figure 6. Actors of interview

\subsection{Role and place of logistics centres in the national transport policy}

The long-term objective of the Latvian transport development policy is to create an effective, safe, competitive, environmentally friendly, balanced and multi-modal transport system, which is fully integrated in the European transport system, and satisfies economic and social needs of Latvia for passenger and cargo transportation in domestic and international traffic. The improvement of the quality of the transport system is one of the main pre-conditions for re-industrialisation and for the development of an innovative economy in Latvia, since it encourages regional development and improves the competitiveness of Latvian companies at the European and international market.

The main directions of Latvian transport policy development are identified in the National Programme for Transport Development 1996-2010. The National Transport Development Programme is a medium term strategic planning document in the transport sector. Its implementation is of vital importance and indispensable for the purpose of the balanced development of the society and the national economy of Latvia. For the full implementation of the National Transport Development Programme there are a range of tasks to be accomplished. Among these tasks are the following: maintenance and development of environmentally friendly transport infrastructure, increasing of traffic safety, promoting and ensuring an increasing performance efficiency of national and international passenger- and freight transport operations, developing transit operations and transit corridors as well as ensuring the integration and competitiveness of the transport system of Latvia in the European transport system.

The National Transport Development Programme (1996-2010) is a most general document of plan character, which constitutes the activities (actions, tasks) of economic, organizational, and institutional nature. It is worked out for a 15 years' period. 
Unfortunately transport research and business and transport policy do not have very close links in Latvia. Freight transit is the main part in Latvia's transport sector. There is a large internal competition between different transport enterprises (e.g., sea ports) and between different modes of transport (e.g., road and rail transport) in Latvia. The profit of transport companies, involved in this transit business, is mainly depending upon political decisions of neighbouring countries but not upon optimisation and logistics decisions. Due to this situation the investments in research as well as correlations between research results and 'real-life' business are very small.

The idea of logistics centre is at early stage of development in Latvia and now is not included in any official documents.

\subsection{Analysis of the questionnaire and interview}

The development of freight terminals and warehouses should be promoted at crossings of transport corridors. In this process the development of logistics is of high importance. As a rule freight distribution centres are developing as joint ventures of private and respective municipal companies.

In the future it is planned to set up freight distribution centres in Riga, Ventspils, Liepaja, Rezekne, Daugavpils and at other principal transport junctions (Figure 7).

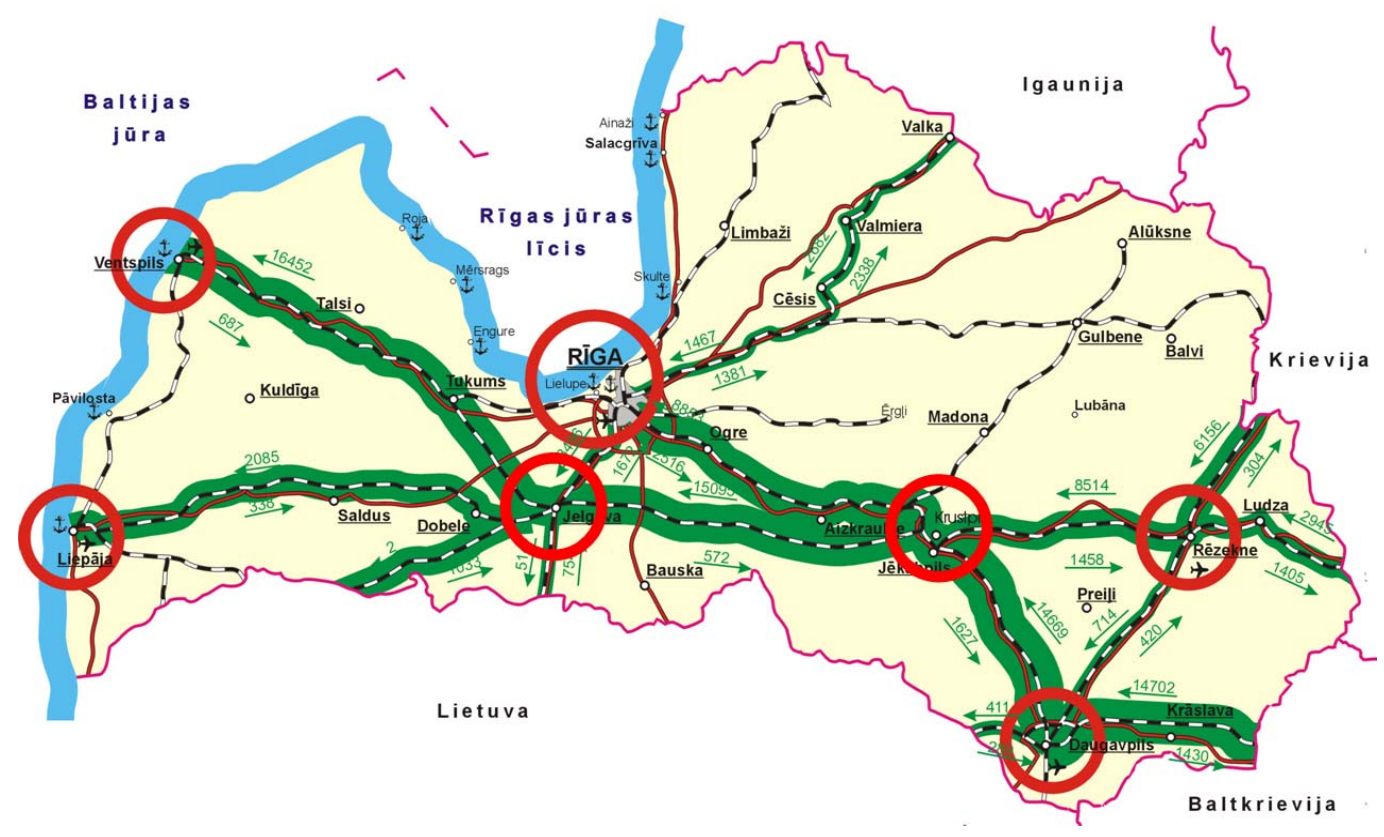

Figure 7. Network of possible LC in Latvia

It is regarded that one of the most important issues for peripheral regions development is the development of logistics and distribution centres focused on attracting freight from Asia and the Far East. Latvia can serve as a distribution centre for cargo from Asian countries (e.g. China, Korea) not only in the Baltic States but also with equally successful results in Russia and the CIS countries. But today the idea of logistics centre is at early stage of development in Latvia.

The main sentences concerning logistics centres, legislation and regulation, land use needs, co-operation between spatial and transport planners and logistics actors are summarised in the next part of report.

\subsubsection{General vision}

1. State spatial planners have not vision on development of logistics centres.

2. Seaport city-regions are key nodes in the global logistics freight transportation network. The maritime activities exploited at the seaport location may promote the regional economic growth of the surrounding because of the circular and cumulative causation a central place is capable to give origin to. The most appropriate regions for logistics centres development are ports of Riga, Ventspils and Liepaja. 
3. Transport policymakers and logistics operators both stress the necessity to build up an efficient transportation system by promoting the inter-modality patterns through the establishment of distribution and inter-modal centres. The seaport city-region should promote the settlement of such public logistics terminals at the local level in order to promote the local entrepreneurship, as well as to reduce the environmental impact of the freight transport within the urban area. The building of the inland logistics terminal at the more far hinterland locations should increase in efficiency the whole transport system because of the promotion of the inter-modality.

4. The three main goals of co-operation between actors are supposed to achieve can be summarised as follows: (1) to establish a more efficient logistics system; (2) to facilitate the implementation of advanced information systems; (3) to promote co-operative freight systems.

5. The LC has to be seen as a meeting point for both public and private logistics operators (Figure 8). The consolidation of the urban logistics activities can be realised at this freight transport node of the transportation network by the application of the most advanced information systems.

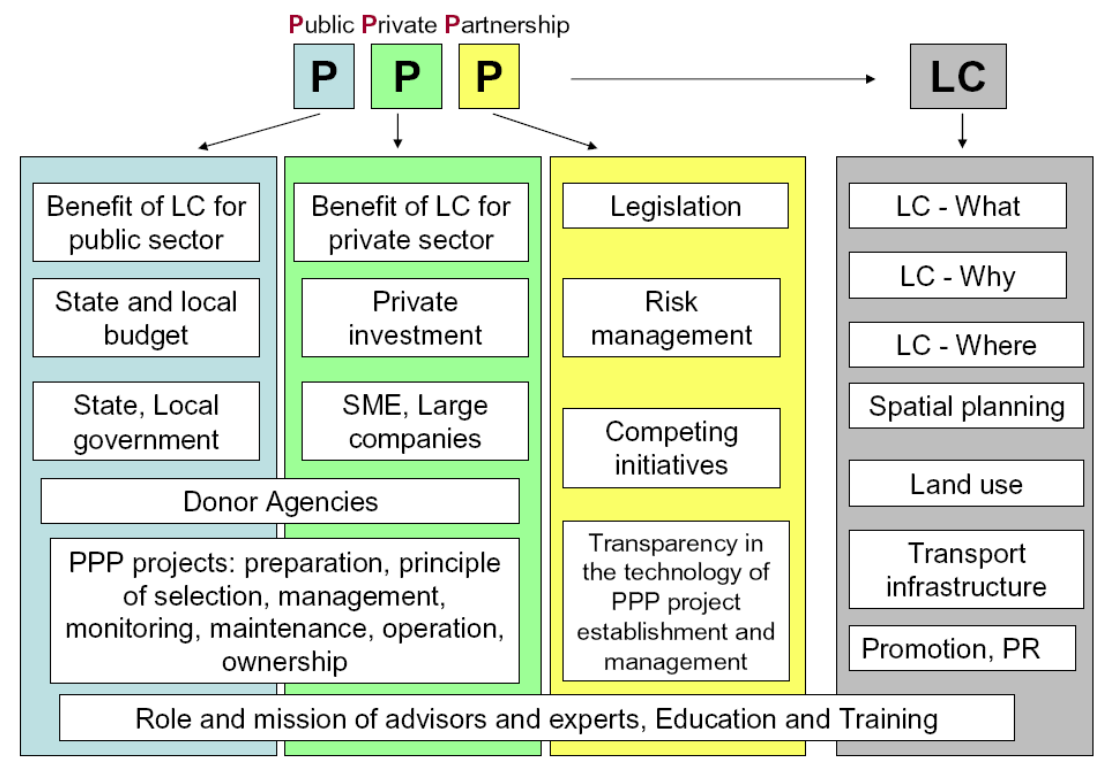

Figure 8. The main tasks for creation of LC

6. An efficient co-operative freight transportation system can be implemented at the LC location. This co-operative system enables a large number of shippers or freight carriers to share a jointly freight vehicles system, jointly terminals, as well as common information systems in order to exploit the synergy effects the spatial agglomeration of the logistics operations spread out.

7. The individual economic agent should be able to reduce the costs for collecting and delivering goods due to the exploitation of the economics of space at the LC. The spatial agglomeration enables the co-operative performance of the logistics operations jointly with other entrepreneurs, as well as the supply to the customer of a level of services of better quality.

8. Through the establishment of a spatial multi-function cluster the entrepreneurship in the logistics transport sector may be promoted, and at the same time the negative externalities generated by the road transport modality may be reduced.

9. The establishment of public logistics terminals in the area surrounding a seaport city can be helpful for promoting the co-operative freight transport systems.

10. The general vision of different actors at the problem of logistics centres development is shown in the Table 1.

\subsubsection{The main problems of the optimal geographical location and the optimal spatial physical size of the logistics centres}

There are two main problems in the development of LC:

- the optimal geographical location and

- the optimal spatial physical size of the LC. 
The location choice among different potential sites has to evaluate the trade-off between transportation cost and facility cost. The facility cost is defined by the sum of the construction, maintenance, land and truck operation costs at the LC site.

The land price plays a major role when the potential nodal location is settled nearby the urban agglomeration. In this case, the lower transport costs the logistic operators had to bear for the pickup/delivery activities between the LC and the urban centres might compensate in such a way the more expensive fixed investments necessary to bin the land, as well as for building the infrastructure.

The public planner should have the role to perform a macroeconomic decision about the more suitable geographical location and dimension of the LC. His aim is to minimise the total cost of the LC. It follows that the accessibility patterns are absolutely relevant.

Table 1. The general vision of different actors at the problem of logistics centres development

\begin{tabular}{|c|c|c|}
\hline Actors of interview & $\begin{array}{c}\text { Relation to idea of logistics centre } \\
\text { development }\end{array}$ & General problems \\
\hline $\begin{array}{l}\text { State level of spatial planning } \\
\text { (Ministry of Regional } \\
\text { Development and Local } \\
\text { Government) }\end{array}$ & $\begin{array}{l}\text { There is no vision on development of logistics } \\
\text { centres. }\end{array}$ & \multirow{3}{*}{ 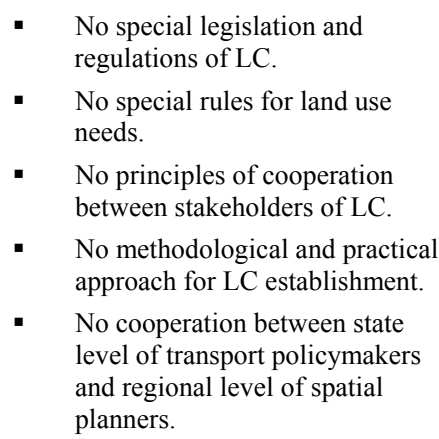 } \\
\hline $\begin{array}{l}\text { Transport policymakers } \\
\text { (Ministry of Transport and } \\
\text { Communications) }\end{array}$ & $\begin{array}{l}\text { There is a sensation of necessity of creation of } \\
\text { the logistics centres, but there is no practical } \\
\text { programme of their development. }\end{array}$ & \\
\hline $\begin{array}{l}\text { Regional level of spatial planning } \\
\text { (Riga and Daugavpils City - the } \\
\text { two largest cities of Latvia) }\end{array}$ & $\begin{array}{l}\text { There is a desire of creation of the logistics } \\
\text { centres, but know-how of their design and the } \\
\text { practical programme of their development are } \\
\text { absent. }\end{array}$ & \\
\hline $\begin{array}{l}\text { Transport and logistics operators } \\
\text { (Transport and logistics } \\
\text { companies) }\end{array}$ & $\begin{array}{l}\text { There is a need of creation of the logistics } \\
\text { centres, but the know-how of their creations is } \\
\text { absent. The mutual competition and mistrust of } \\
\text { transport operators to each other essentially } \\
\text { interferes with the decision of practical } \\
\text { questions of LC creation. }\end{array}$ & \multirow[t]{2}{*}{$\begin{array}{l}\text { - No practical experience in pilot } \\
\text { project of design and } \\
\text { development of LC. } \\
\text { Transport transit much more } \\
\text { outnumber of distribution at the } \\
\text { state level. }\end{array}$} \\
\hline $\begin{array}{l}\text { Transport and logistics research } \\
\text { and education establishments }\end{array}$ & $\begin{array}{l}\text { There is a sensation of necessity of creation of } \\
\text { the logistics centres; there is a general vision } \\
\text { on development of logistics centres. There is } \\
\text { no demand from the other actors. }\end{array}$ & \\
\hline
\end{tabular}

Among all the potential proper places, the location choice of the public planner should be addressed in favour of the geographical site closer to the major inter-modal transport links, which connect the urban agglomerations that had to be served by the new settled LC. If any congestion problem already exists, then an inappropriate location decision of the traffic policy planner might induce a worsening in the road traffic conditions within the region.

The improvement in the efficiency of the road network can significantly help to mitigate the negative economic impact the spatial traffic congestion induces, which is reflected by the increase in the transportation costs.

The public planner has no influence at the microeconomic level of decision, when the distribution and assignment of the freight traffic is considered.

At a micro level, where the individual transport operator decides to use his own freight vehicle, the choice of making a stopping call at a certain LC rather than another is supposed to be determined by the behaviour of the single transport operator or company. At this level of choice, the goal is to minimise the transport costs (Table 2).

The structure of the transportation sector has not to be forgotten. The freight transport is generally undertaken by individual entrepreneurs and private companies, which operate within a competitive market framework. Hence, the control and regulation measures put in force by the regional public planner should not excessively interfere with the activity of the transport sector.

Besides the transport policy instrument of the LC several other city logistics initiatives have been proposed in order to overcome at the best all the negative externalities the urban freight transport generates. 
The freight transport carriers' fire expected to provide economically efficient just-in-time services. This means that the minimising of the transport and logistics services should be achieved. At the same time, some urgent problems had to be solved, such as the traffic congestion, the environmental impact of the transport activity, as well as the problem of the energy conservation.

Table 2. The public logistics terminals and the two levels of decision

\begin{tabular}{|l|l|l|}
\hline \multicolumn{1}{|c|}{ Level of Decision } & \multicolumn{1}{|c|}{ Kind of Decision } & \multicolumn{1}{c|}{ Goals } \\
\hline Macro level: Public planner & $\begin{array}{l}\text { Location choice, and optimal size } \\
\text { of the LC }\end{array}$ & $\begin{array}{l}\text { Min the total cost }= \\
\text { Min (transport cost }+ \text { facility cost) }\end{array}$ \\
\hline $\begin{array}{l}\text { Micro level: Every entrepreneur, } \\
\text { each company and freight vehicle }\end{array}$ & $\begin{array}{l}\text { Choice of the LC and optimal } \\
\text { routing }\end{array}$ & Min the transport cost \\
\hline
\end{tabular}

The crucial role played by the public-private partnership is always stressed on when speaking about the city logistics initiatives. Besides the LC the implementation and diffusion of progressive information systems in order to organise the routing and scheduling of the consignments in advance, the promotion of co-operative freight transport systems, the control of the load factor for the pick up/delivery activities, as well as the planning of the must innovative underground freight transport systems are all potential instruments of transport policy the regional public planner had to consider and properly evaluate.

\subsubsection{Advanced Information Systems}

The improvement of advanced information systems is one of the most relevant instruments in order to achieve the rationalisation in the logistics activity. Planning in advance the routing and scheduling of the consignments may effectively improve the efficiency in the transport system.

The advance information systems enable both the drivers of the trucks and the control centre to communicate to each other, to provide the information on the traffic conditions in real time, as well as to store detailed historical data about the pickup/delivery truck operations. In particular the last function plays an important role for rationalising the logistics operations.

The most important findings beyond the particular ease are as follows:

- Large customers (shippers) require logistics partners (forwarders) to either accept paper input (primarily fax) or to subscribe to customer's choice of technology. Such customers are unlikely to reimburse their partners for related effort, the implementation thus have to bear sufficient saving potential for the forwarder;

- EDI data transmission and the relating process automation provide the basis for improvements of transport planning and execution. This results not only in commercial benefits but may eventually lead to a reduction in unnecessary transport (e.g. empty legging) and a better utilisation of public and commercial infrastructure (e.g. roads, floor space and terminal equipment);

- Port community systems provide the technical, managerial and business background to implement EDI systems. While they are normally successful in linking the majority of directly port related companies they are traditionally weak when it comes to hinterland companies;

- Linking only one additional exporter or importer in the hinterland may have very significant multiplication effects. The company may communicate with additional partners in the same and in other ports. Likewise the resident logistics partner has been enabled to also communicate with other hinterland partners;

- A success factor is the usage of standardised communication and messages. In transport EDIFACT has the largest user base.

Computer based information systems in transportation chains have several advantages:

- Increased management options through tracking and tracing and improved quality control of own services and those of subcontractors;

- Outsourcing of transport services, but staying in control of logistics performance;

- Increased production-to-order orientation and better transparency of market demand and supply.

Information infrastructure is a major component of all mentioned above factors. The transportation information infrastructure designed for transportation system has a number of attributes and components, some of which will be provided by private transportation companies and some of which must be provided by the public sector. 
The national R\&D program defines the following research tasks.

1. Basic concepts and standards for transport information system:

- Needs and purposes of the information system.

- Common definitions and standards.

- Specification of data requirements.

2. Analysis of existing transports data.

- Aggregation and harmonization of existing data.

- Applicability of existing methods of data collection on transport flows.

- Data on transport flows (including flows along pipeline and dangerous goods).

- Data on determining factors of transport patterns and demands.

- Transport network data.

- Guidelines for data structures and maintenance.

3. Scheme for certain immediate actions of data collections:

- Goods and passenger flows into and out of the state.

- Long distance goods and passenger movements between regions within state.

- Major infrastructure projects and their effects on traffic induced by network enhancement.

- Data on intermodal transport.

4. Methodology for establishing general databases on transport flows and socio-demographic data:

- Zoning system and definitions.

- Demographic data.

- Socio-economic data.

- Transport volumes and values, traffic flows (including modal split and mode specifications).

- Data presentation (including flows, time series and cross-sections).

- Integration of user requirements.

5. Methodology for establishing databases on transport infrastructure networks:

- Geographical structure.

- Definitions and standard indicators.

- Physical data.

- Performance data, others.

- Integration of user requirements.

6. Methodology for collecting specific data sets for modelling, methodologies, scenarios and assessment:

- Externalities.

- Factors affecting demand and supply of transport (including logistical data).

- Modal choice and modal split.

- Inventory of state aid.

- Others (databases of transport studies and experience, of areas affected by transport, of people with mobility handicaps or special mobility needs, etc.).

- Integration of user's requirements.

7. Methods of data analysis:

- Analysis requirements.

- Identification of appropriate methods for various types of data (generalized linear models, spatially auto correlated data, correspondence analysis, etc.).

- Recommendations and guidelines.

8. Methods to obtain transport data cost-efficiently:

- Collection and measurement methods (considering the differences between modes in terms of data availability and the use of new technologies).

- Methodology approaches (for distinction between transit flows and regional flows, etc.).

- Costs of alternatives.

9. Structure and maintenance of the transport information system:

- Database principles (updating period, accessibility, etc.).

- Data presentation techniques (including information linked to the data).

- Application and suitability of new technologies for automatic data collection, processing and presentation.

- Human organization, institutional requirements and coordination aspects (exchange and dissemination of information). 
The design process of information infrastructure model for multimodal transport system may be presented by five-level hierarchical structure (Figure 9):

- 1 level - The system concept for general model of integrated transport information infrastructure. (The development of appropriate system approach in modelling will be a key topic of research and linked with the areas of investigation mentioned above to ensure harmonized models and methodologies at the state level).

- 2 level - Development of external scenarios and models to describe the causal relationships between external factors and mobility and for presentation of mobility patterns, transport flows and scenarios.

- 3 level - Development of macro level models served for representation of the whole traffic structure that combines the four transport modes: road, railway, water and air systems.

- 4 level - Development of micro level models represented logistics processes at the specific points of transfer corridor: the boarder crossing places, air and sea ports, railway stations and custom's warehouses.

- 5 level - Assessment of transport policy requirements for the integration of information, communication and navigation technologies.

Information infrastructure will develop largely through private sector. The role of government in information infrastructure is likely to be more similar to its historical role in communication than to its role in physical infrastructure of transportation. It is important to develop partnership between the transportation and information communities.

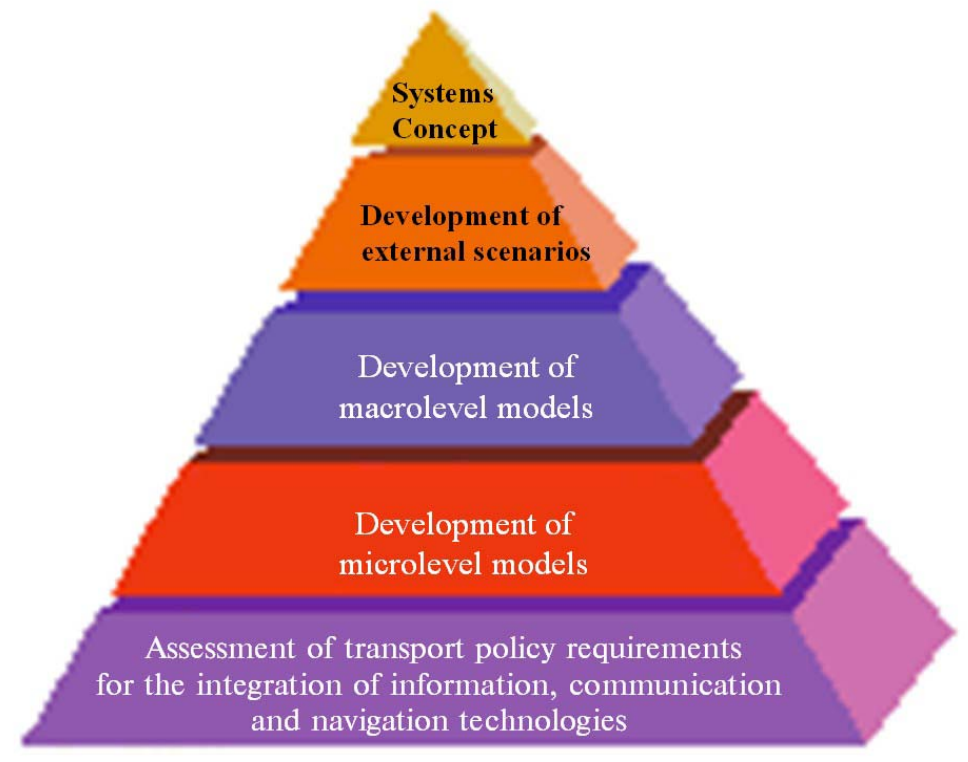

Figure 9. The Design Process of Information Environment

\subsubsection{The Inter-regional Level}

At the inter-regional level, the programme instrument should enable the integration between seaport regions by following the broader issues of network connectivity and logistics. The three fundamental network characteristics of (1) inter-modality, (2) interoperability and (3) interconnectivity should be achieved in order enlarge the value-added to the seaport network.

A coherent collaboration programme between the seaport regions should particularly emphasise the benefits of its realisation, in order to attract as many potential private/public investors as possible. The regulatory and organisational framework represents a valid tool of transport policy, in particular when the negative externalities generated by the different transport modalities are not completely internalised into the market price of the transport service. The under-pricing in the transport sector occurs when a transport modality hides its full social cost. The structure of the transport sector is typically shaped as an imperfect competitive market system, which is assumed to allocate inefficiently the economic resources. Hence, the under-pricing in the transport service shows the lack in efficiency of the market instrument of allocation. The larger the share of the full social cost a transport mode is able to hide, the sharper the under-pricing it may form. 
The new economic figure of the Multi-modal Transport Operator (MTO) is assumed to exploit the provision of the logistics services within a wholly integrated transport network. The Table 3 summarises the key issues and the critical patterns of success at the inter-regional level of decision.

Table 3. The inter-regional level of decision

\begin{tabular}{|c|c|}
\hline Key Issues & Critical Success Factors \\
\hline $\begin{array}{ll}\text { For each transport modality: } \\
\text { - } & \text { Inter-regional links } \\
\text { - } & \text { Inter-modality } \\
\text { - } & \text { Interconnectivity } \\
\text { - } & \text { Interoperability } \\
\text { - } & \text { Logistics and networking effects } \\
\text { - } & \text { Competitiveness } \\
\text { - } & \text { Environmental issuer } \\
\text { - } & \text { Information network } \\
\text { - } & \text { Economies of scale } \\
\text { - } & \text { Economies of time } \\
\text { - } & \text { Economies of scope } \\
\text { - } & \text { Economies of networking } \\
\text { - } & \text { Just-in-time requirements }\end{array}$ & $\begin{array}{ll}\text { - } & \text { Functional collaboration and competition } \\
\text { - } & \text { Interchange of complementary functions } \\
\text { - } & \text { Iransport network } \\
\text { - } & \text { Information and knowledge interchange } \\
\text { - } & \text { Multi-modal transport operator } \\
\text { - } & \text { Adding value to the interregional network and } \\
\text { - } & \text { communications } \\
\text { - } & \text { Favourainable balanced growth between regions } \\
\text { innovative space }\end{array}$ \\
\hline
\end{tabular}

\subsubsection{The National Level}

At the national level, the programme of LC creation is once again a powerful instrument of transport integration and co-ordination. Logistic effects and networking effects have to be considered in order to exploit a sustainable national transport policy. The freight transport by road seems to fit better the new logistics requirements due to the restructuring process in the supply chain of production. The environmental and social impacts of the transport negative externalities are not completely internalised into its market price.

The under-estimation as well as the under-pricing of the road transport modality has a remarkable impact on the modal choice of the economic agents, due to the apparently higher efficiency this environmental unfriendly transport modality shows with respect to the others. A careful estimation of the real impact of the negative externalities on the national economic growth should be estimated in monetary terms to calculate the "green" GDP.

There are three possible approaches in order to estimate and/or internalise of the negative transport externalities: the consumer-pays approach, the taxpayer-pays approach, and the cost-benefit analysis.

Furthermore, the logistics companies look for a central location as basis for their logistics activities directed to their international clients, as well as a departure site in order to enlarge their commercial relationships. A relevant role is played by the technological changing in the loading/discharge operations, as well as the increasing availability of space within the neglected old port areas. At these locations, the logistics service companies may find an interesting supply of space to turn into their activities.

From a functional point of view the three Latvian main ports are involved in an international maritime competition. A complementary set of functions should be promoted at each seaport site in order to lead to a better integration in the transportation chain, as well as in the road and rail links between the three seaports.

In fact, the transport links from the seaport site towards the hinterland have to perform an increasing efficiency in order to attract the shipping companies, and moreover the specialist total logistics provider.

All actors stress the necessity to build up an efficient transportation system by promoting the intermodality patterns through the establishment of distribution and inter-modal centres. The seaport cityregion should promote the settlement of such public logistics terminals at the local level in order to promote the local entrepreneurship, as well as to reduce the environmental impact of the freight transport within the urban area. The building of the inland logistics terminal at the more far hinterland locations should increase in efficiency the whole transport system because of the promotion of the inter-modality.

Many different and interdependent factors usually influence the location choice of an economic agent. Few decisional patterns may not be spatially relocated such as the transport infrastructure, the urban settlement, or the environment. Others are more flexible and may be subject to spatial relocation, e.g., the skilled labour force, the research centres, etc. 
The accessibility to a seaport site is therefore strictly dependent on the optimal combination of all these elements. A seaport region might be consequently more or less attractive to the establishment of an economic activity or to the foreign investments in order to exploit its own local development potential.

In order to support the overall LC objectives a close co-operation with similar projects and programmes must be established:

- to strengthen the integration of spatial planning and regional transport development and develop a common regional approach to the issue of sustainable logistics solutions,

- to promote the use of transport corridors, modes and technologies, which support a sustainable regional development providing the economic and social development of the regions in the southeast part of the Baltic. The trans-national co-operation aims at assessing trade and transport potentials and develops environmentally friendly transport solutions.

\subsubsection{Framework for regional action}

As it has been already analysed it would be inadequate to recommend "one best way" for spatial planning within the context of port related interaction in general and in BSR in particular. The main reasons to be careful with strong recommendations may be summarised as follows:

1. The spatiality of transport and logistics activities has evolved from clearly delimited port areas to functional port regions and to port networks more recently. The functional interdependencies, creating the network, may consist on sequential relations (output of one node is the input for another, e.g., relation between port and in kind container depot), reciprocal relations (actors arc using each others output) and pooled relations (use of common resources). The term network suggests that these interdependencies may not be territorial and that modern port related activities have a strong tendency towards decentralisation.

2. The trend of a spatial decentralisation of port related transport chains is accompanied by attempts of the main actors involved to achieve control over the segments of the chains. Though it is not clear whether one actor will be the most influential one in the future, the entrepreneurial strategy is not predictable in relation to their spatial outcome. But it is rather obvious that the crucial factor within the transport chain will be the customer orientation while the transport space will be organized as flexible as possible. This interpretation supports decentralized hub and concepts with, "footless" or shifting nodes. Based on some standardized norms the question of appropriate IT support will depend on the dominant position of an actor within the transport chain. Or to put it in other words: the inventions and early adaptation of new IT depends on the necessities to optimise integrated transport and logistics chains and the economic power of private actor constellations.

Following these lines of argumentation the existing ports have to deal with territorial decentralisation of transport and logistics activities and tendencies of economic centralization of private actors involved. Therefore the frames of independent action become more and more narrow. In more general terms, existing ports do not only have to create and sustain competitive infrastructure including IT but have to be prepared to offer far reaching services for foreign trade, transport and communication in order to be able to react as flexible as possible to new challenges. Beside an effective node of physical interchange successful ports will become LC regions for transport and communication offering systemic knowledge for integrated transport and logistics chains.

This strategy is open only for the existing main ports and those medium-sized ports are able to promote a certain specialisation because it presupposes very high investments and probably only indirect returns on welfare and employment. Small and the majority of medium-sized ports will function as possible nodes in future transport chains. This implies the latent danger that many ports try to invest in expensive infrastructure in order to compete with each other without being able to realize returns. A crucial element is finding a certain harmony between public investments in infra- and private engagement in the superstructure. Anyway, problems of public disinvestments are already on the agenda and there is a latent danger for continuous planning failures. To reduce an overall port competition in this segment institutionalised forms of information and co-operation between private and public actors should be promoted in order to avoid unnecessary public investments and to improve power balance.

Faced with the imminent enlargement of the European Union and the integration of Latvia as well as further states of the Baltic Sea Region a general strategy of the modernization of the maritime infrastructure is to be recommended including IT. The expected increases of transport will not be manageable country-sided in spite of great infrastructure projects like Via Baltica. The expansion and improvement of sea-based mobility of goods and supporting infrastructures should be emphasized in initiatives of spatial planning within the Baltic Sea Region. 
Also in the transport and logistics sector the major players are changing. Former State Enterprises are privatised and must prepare themselves for the sudden competition. Just as the governmental telecommunications monopoly was eliminated in previous years, the state monopoly on the transportation of letters and parcels would now be eliminated too. These modifications of the general conditions lead to hectic activities within the sector. Many re-evaluate their middle- and long-term strategies, reposition themselves, co-operate and merge, withdraw from some markets and set themselves up in other ones. Cooperation with, or the incorporation of, other companies is the most usual reaction to the new conditions, in the transport and logistics sector as well.

But according to opinion of the actors involved, both growths are important as quantitative so as qualitative. The new demands of the information society and the "New Economy" on the transport and logistics sector, make it necessary to increase the "know how" as quickly as possible in the field of IT, and develop information systems wherewith the logistics chain can be controlled and checked. IT departments of individual companies are no longer able manage such a task, so that big actors (e.g., the Latvian Association of Railway International Electronic Documents Circulation Operators) buy up software enterprises throughout the world that develop information systems for the transport and logistics sector, or will be able to do so in the future. All actors participating in the transportation chain are convinced that the future leader of the information system will also dominate the material transportation chain and thereby gain the largest part of the increased value created by transportation. Furthermore, the evolution of such technologies is extremely capital-intensive: markets, which are becoming more and more transparent, involve ever-increasing costs for marketing and distribution. Smaller enterprises, endowed with a more limited capital, are no longer able to make the investments necessary to remain competitive.

\section{National Transport Research Program}

The investment priorities are defined within the framework of trans-national requirements and local development needs. On the one hand, there is potential for Latvia to play more important role in transportation of cargo and people in international transport. There already is a substantial flow, mainly of freight traffic, in the direction East-West and it is expected that following the increasing integration of the Baltic States into the EU, traffic flows in North-South direction will increase as well. In order to utilise this potential, there is a need for significant improvement of infrastructure, particularly by reconstruction of railway hubs, building of railway tracks, modernization of train service management automatic systems, introduction of joint railway mobile communication system GSM-R; reconstruction of the main motorways, building of new sections, double level crossings; building of access roads and railway tracks to the ports, passenger terminals in the ports; modernization of airport infrastructure both in Riga international airport and in regional ones; as well as building of access roads to the TEN-T network in urban areas. Cohesion Funds can substantially tribute to the achievements of these goals.

On the other hand, there is a need to ensure higher mobility of the population and labour force in order to advance the economic development of the country. Latvia has to improve the living conditions of the rural population, particularly in terms of access to social and economic infrastructure, in order to avoid emigration of population to Riga and other countries.

The decision of these global tasks will be done for Latvia within the frame of National Research Programme (NRP). Harmonisation of Latvian Transport System (project LaTRANS) is one of the key NRP subprogramme. The aim of the project is to develop the efficient, safe and environmental friendly handling of the increasing amount of goods going east-west in the Baltic region. The project will prepare stakeholders in the region to enhance sustainable transport planning and smart intelligent transport solutions.

This in combination with business development in the transport sector will stimulate the economic growth in the entire East-West transport corridor. There are three main focuses in the project:

- To make East-West transport corridor as a good example of a Green Corridor concept of European Union latest transport policies.

- To develop an innovative pilot testing ground where modern technology and information systems contribute to increased efficiency, traffic safety and security as well as reduced environment impact in the corridor.

- By stimulating new business models e.g., for railway transport supporting economic growth within the corridor in particular in ports and inland hubs. 


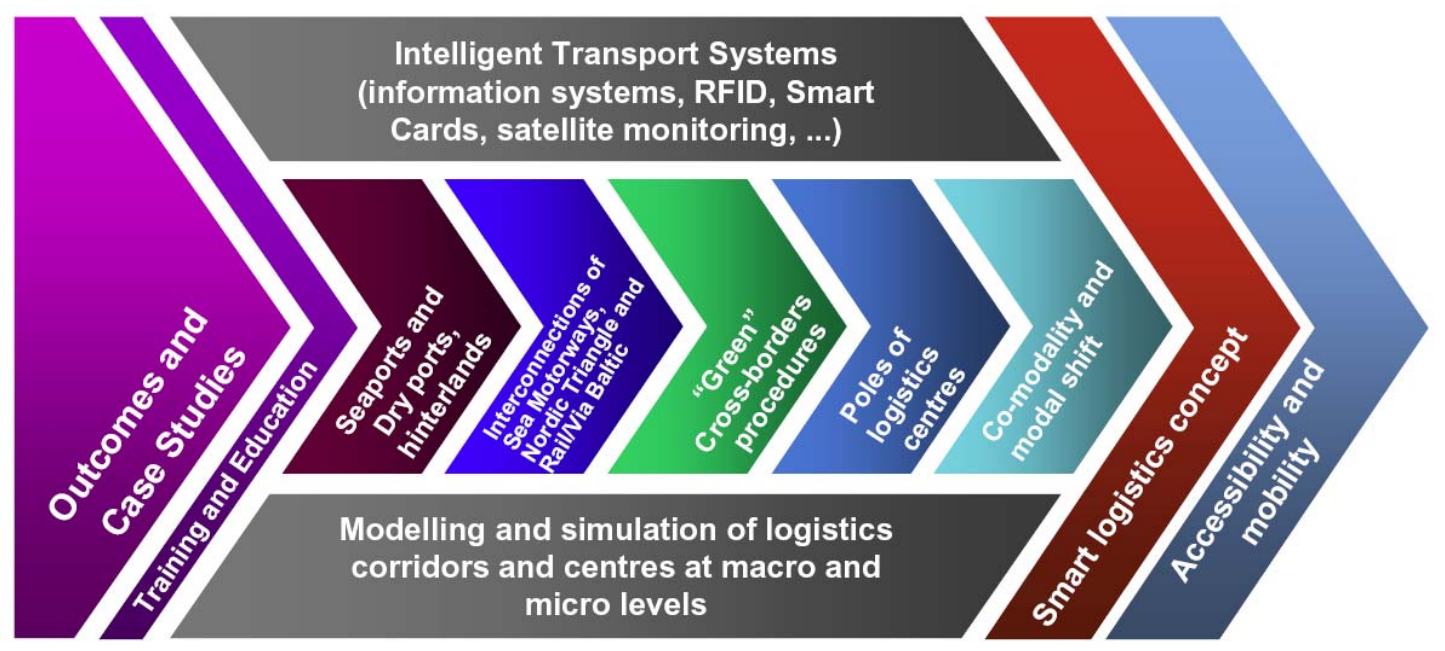

Copyright $\mathbb{C}$ Kabashkin, 2010

Figure 13. Structure of the national research project LaTRANS

The main expected results of the project:

- East-West transport corridor as a Best Practice Case for Green Corridor development;

- East-West transport corridor as a part of the EU commissions Action Plan for the Baltic Sea Region and is an integrated part of the Northern Transport Axis [6];

- A manual of how to develop a Green Corridor in accordance with the EU's transport policies and to offer stakeholders in the East-West transport corridor more eco-friendly transport alternatives than available today;

- An innovative Intelligent Transport Systems for transport and traffic information, which will increase efficiency and reduce the environmental impact;

- A manual of how to buy, sell, and plan eco-friendly transports, transport and logistics services, which can be used by different customers;

- New business concepts for railway transports;

- Improved transport service in ports and terminals;

- Increased transport competence among various stakeholders and improved infrastructure within the transport corridor.

For ensuring a sustained response to permanently growing demand for mobility, the transport of Latvia should develop in a dynamic manner and integrate in the European transport system.

The development of transport in Latvia is based on a principle of sustainable development:

- integration among different modes of transport;

- integration in the environment in order to diminish harmful impact on it;

- integration with the land usage planning so that transport and land planning works are mutually co-ordinated which leads to the possibility of choosing the most suitable mode of transport;

- integration with education policy, ensuring of health care and welfare in a manner the transport contributes to formation of an integrated society.

The goal of the transport development policy of Latvia continues to be setting up of an efficient, safe, environmentally friendly, multimodal, balanced and competitive transport system. Its integration into the European transport system is anticipated thereby meeting the economic and social needs for high quality transport services as well as increasing possibilities of transport mode choice and flexibility of passenger and goods transport operations.

\section{Conclusions}

As discussed earlier in this study, it is important to remember the market forces, even when discussing the development of sustainable transport solutions from a spatial planning perspective. The demand for freight transport services is generated and formulated by individual entrepreneurs and private companies, which operate on highly competitive markets. This obviously limits the possibilities to guide 
the development in a specific geographical area. It puts high demands on planning to be flexible and on the foresight of the planners. On the other hand good public infrastructure, e.g. the road system, also helps to attract business and to improve efficiency.

An attractive and competitive port is often considered as a regional, if not a national objective supporting the economic development of the region or the nation. Traditionally, the consequence of this view was as follows - the port operation and the related infrastructure was a public responsibility. Today, port operation is no more considered as a suitable or even acceptable task for public services. Some regions are starting to question the need for any public involvement in port business. Why should a city own a port? It does not own the marshalling yard or the truck freight terminal.

Such ideas do not mean that the city should not plan for or care for its port only that it must distinguish between public and business objectives. Local political opinions, competition with neighbouring regions and lack of overview might induce the city or the region to invest too much in relation to a realistic assessment of the commercial outcome.

Waterborne transport of high value goods needs to offer high frequency of regular services and stability over several years in order to be competitive to other modes and to really allow for the emergence of solid trade relations. A few well-served ports also make it easier to focus national investments in the hinterland infrastructure, which normally cannot be spread out to cater for too many alternatives. Competition between regions in this respect often delays the investment decisions. In addition, stable and big transport volumes also on land open for more attractive intermodal services.

In this context it might be worthwhile to question the benefit of transit traffic; through the port, the city or the region. The issue was raised in relation to the Russian transit traffic, but is also valid elsewhere. Investment needs and environmental impacts have to be assessed in relation to job opportunities and revenues against an appraisal of the stability of the traffic. Transit transport might help to develop new and highly needed services and skills, but it might also deviate resources better used elsewhere and might create e.g. environmental damages difficult to repair.

Co-operation between the parties in a transport chain, between ports, regions and authorities can give concrete improvements to everyday practical problems and thus contribute to the goals of cohesion and economic development in the Baltic Sea region. The results have been achieved in a highly competitive environment and indicate that there are areas for co-operation, which do not distort competition, but promote a sustainable transport system to the benefit for the society as well as the private players. Such areas are the following:

- $\quad$ Promotion of the use of IT among the port community and between the port and the world outside.

- Introducing IT in the business process is a complex issue affecting internal and external procedures, core business ideas and market positions. Building efficient IT relations between authorities and private organisations requires special attention. E-business development suggests that Internet will speed up the reorganisation of commercial relations and market behaviour. Apart from infrastructure, companies need some basic agreements on standards. The public sector on a national, regional or local level can act as a catalyst in this process.

- Co-operation between customs and other authorities in specific transport corridors.

- Goodwill and mutual trust is a good basis for solving practical problems within an existing regulatory framework. Regional authorities along a transport corridor sector can together create the platform for such facilitation work. They can bring in all parties and moderate the work of creating a common understanding of the problem and hopefully also have finding a practical solution.

- Regional co-operation between public bodies and private companies in order to understand spatial needs based on the assessment of long-term commercial trends for waterborne transport and other factors affecting future transport demand.

- A port is acting and reacting on developments far beyond the region in which it is situated. Infrastructure investments in competing transport corridors have to be assessed as well as new commercial constellations and technical development. Spatial and economic planners have to understand the needs and prospects of the port in order to be able to assess the consequences for the region.

- Implementing new networks between transport companies, scientific organisations and port cities. A modern LC can be characterised as an important node in a learning region, which in addition implies the need for co-operation with other, similar regions. What has been said earlier also indicates that there are other reasons for networking. A "market watch" in a wide sense is required not only by the commercial players, but also by other institutions in the region in order to be able to assess planning and investment needs. Another need for 
networking is generated by the many practical problems of becoming a true European Union. Knowledge, trust and common objectives across former borders could be better developed through co-operation around particular problems.

The port region logistics restructuring process moved towards the development of new economic functions inside the port region itself. The aim of the local authorities has now become to offer a set of value-added logistics services in order to integrate the port site into the transport logistics chain. The port location is not to be only a container floodgate but is to be transformed also in a logistics service centre.

It is not surprising, that logistics centres tend to be located near the transport corridors. Access to all transport modes is vital for the success of logistics centres. The closeness to ports and sea transportation is natural for establishing a logistics centre in Latvia.

Many aspects of the operation environment need to be taken into account in the planning of logistics centres. Co-operation between the logistics centres and the actors responsible for the design and production of infrastructure is important especially in planning infrastructure projects to be carried out on routes near logistics centres.

Attention should be paid to environmental protection and legislation at the early stages of the planning of logistics operations and infrastructure. Land use conflicts based on environmental regulations may otherwise delay the logistics development projects considerably. This is one of the main challenges for the development of the logistics centres in Latvia. The possibilities for co-operation at the municipal level for the promotion of logistics should be thoroughly analysed.

The success of ports and logistics development projects depends strongly on the development of transit traffic.

The harbour will form a core area in a wider concept of activities in the adjacent area of the city. Such activities might be many kinds of international, national and local commercial activities, logistic firms, consulting and transport services, etc. Together with the harbour itself, this will form a logistics centre in the region as well as a transport hub (multi modal centre).

\section{References}

1. CPMR Baltic Sea Commission. (2005). Transport Challenges in the Baltic Sea Area: Report by the CPMR Baltic Sea Commission. Work Group Transport. Brussels

2. Arvis, J.-Fr., Mustra, M. A., Ojala, L., Shepherd, B., Saslavsky, D. (2010). Connecting to Compete. Trade Logistics in the Global Economy. The Logistics Performance Index and its Indicators. Washington: The International Bank for Reconstruction and Development /The World Bank.

3. European Commission. (2007). The Freight Logistics Action Plan. COM (2007) 607 final. 18.10.2007. Brussels: European Commission.

4. Kabashkin, I. (2007). Logistics Centres in the Baltic Sea Region - Case Study in Latvia: Research Report 183 of Lappeenranta University of Technology, Value Adding Role of Logistics in Northern Europe (pp.145-170). Kouvola: Lappeenranta University of Technology.

5. Henttu, V., Lättilä, L., Hilmola, O.-P. (2011). Optimization of Relative Transport Costs of a Hypothetical Dry Port Structure. Transport and Telecommunication, 12(2), 12-19.

6. Yatskiv, I., Savrasovs, M. (2010). Development of Riga-Minsk Transport Corridor Simulation Model. Transport and Telecommunication, 11(1), 38-47. 